\title{
CREDIBILITY OF SOCIAL ONLINE MEDIA: IN THE EYES OF FINNISH PROFESSIONAL JOURNALISTS
}

\author{
Mohammad Ofiul Hasnat \\ ohasnat@ulapland.fi \\ PhD candidate - University of Lapland, \\ 96100, Rovaniemi - Finland
}

\begin{abstract}
This article reviews the changed structure of news presentation in the social media, addressing concerns about credibility and ethics. It highlights the important factors of accuracy and trustworthiness to measure newsworthiness and credibility of the news of social media. Possible ideas for editing social media contents have been suggested as absence of a gatekeeping process has raised question about the credibility of the social media. The study analyses contents of theme interviews conducted with selected journalism professionals from four newspapers: Lapin Kansa, Kaleva, Keskipohjanmaa and Österbottens Tidning in Finland. The results show that the social media started to serve the purpose of people getting news and will emerge as full-fledged news media in future, if the authenticity, credibility and transparency of information could be ensured upholding journalistic ethics.
\end{abstract}

KEYWORDS

Social media; news; credibility; ethics; professionalism

\section{INTRODUCTION}

Citizen journalism in various social media created the possibility of reading news on Internet, which in turn prompted the established news organization to practice online journalism. Two type of online journalism: professional and nonprofessional, had a significant impact on news production, where controversy regarding the credibility of information is an important issue now. Although the social media brought a new dimension to the field of mass communication and journalism, absence of professional knowledge and institutional structure may create a risk of non-credible information, as there is no gatekeeping process for the flow of information. The pattern and news production of the social media is also different to the traditional journalistic concept which may create confusion among the readers regarding transparency of the information provided by the private communicators. Question also raised, whether the new form of journalism performs responsibility from the context of ethical and journalistic norm.

The characteristics and nature of the traditional and social media are different so it is not easy to reach an understanding about the credibility of social media and it is difficult to justify the necessity for comparing different types of media on credibility issues. As there is no specified indicator for evaluating the credibility of mass media, other than pointing out the sources of the news to ensure authenticity, the definition of credibility might be different for the online media, as the news is being disseminated hurriedly 
there. The social online media are mostly private and performed by amateurs, but the information is being disseminated publicly. In most cases the social media disclose information based on primary sources and as a result they are usually very close to the facts. The social media also have a significant impact on the traditional news media such as printed newspapers, radio, and television, although the impact is not similar everywhere due to different social, economic and political situations. The traditional news media are facing a challenge in Finland, as they are elsewhere of the world, because of the expansion of digital media, which forced the traditional media to think about alternative ways to survive. Most newspapers have already started online versions in addition to the printed version. Besides that, the shape of the traditional newspapers is also changing. The Lapin Kansa, leading newspaper in Lapland and the Helsingin Sanomat, the biggest newspaper in Finland, became tabloids in 2012 and early 2013 respectively. The authority of two other regional newspapers, Ilkka and Pohjalainen, in mid-February, 2014 announced to bring tabloid version following fall of sale and incurring losses. Tabloidization does not mean only a new form for the newspapers. It also has changed newspaper and media in a broader sense to be more entertaining.

The article written based on the results of the theme interviews with the journalism professionals in Finland and some theoretical analysis, points out how the social media are maintaining the credibility of their news. As a part of the credibility, the authenticity of the information, transparency in news management process and professional practice from the ethics of journalistic points of view were discussed.

\section{METHODOLOGY AND SUBJECT MATTER}

This article is written based on the results of theme interviews and the results of some previous researches done by other researchers. The qualitative data analysis method was followed in the study. The qualitative research generates statistics using the results of the structured interviews. The linking process of the answers was not so difficult as the respondents were from the same profession, although their categories, position and experience were different. The data is analysed by theme independently. The opinions of news professionals regarding the credibility of online media were analysed following the thematic analysis of the qualitative research in Arithmetic mean manually. Focusing the role of the professional journalists as an important factor in the use of information from social media in their news organisations, a methodology of close observation of journalists at work was emphasized in the study, resulting in rich empirical material containing first-hand primary information about newsroom production. As the study was limited to only a few cases, generalization is difficult. The case study therefore primarily serves as a 'reality check' on the theoretical discussions above.

However, measures can be taken to avoid many of these methodological pitfalls. The most important is to ensure a triangulation of approaches that secure different perspectives on the material. As the triangulation process increases validity by incorporating others viewpoints through verification, the observations should, therefore, be accompanied with interviews and document analysis. 


\section{THEME INTERVIEW}

The structured theme interviews have been conducted with working journalists involved in both the online and printed versions of the newspapers. The face-to-face interviews were conducted from March 2012 to October 2012 separately at the respective newspapers offices. The interviews were recorded in addition to taking note in writing. Written scripts of the questionnaires were supplied to the journalists beforehand. The recording helped to analysis the data as most of the journalists pointed out various aspects of the questions from their own points of views in different ways. A total of twelve journalists, three of Kaleva, four of Lapin Kansa, three of Keskipohjanmaa and two of Österbottens Tidning were interviewed. Antti Kokkonen, chief editor; Antti Ylönen, web manager; Milla Sallinen, web producer; and Suvi Tanner, news desk editor of the Lapin Kansa; Markku Mantila, editor-in-chief; Erkki Hujanen, community news editor and Janne-Pekka Manninen of the online news desk of the Kaleva, Lassi Jaakkola, editor-inchief; Jukka Lehojärvi, head of the visual department and Riikka Sipilä, online editor of Keskipohjanmaa; Margareta Björklund, editor-in-chief; and Sofia Grankull, online editor, of the Österbottens Tidning, shared their experiences and thoughts regarding credibility during the interviews, in addition to answering the formal questions.

\section{QUESTIONNAIRE}

The questionnaire for the interviews consists of 30 questions, including some supplementary questions. The major questions were regarding credibility and ethical aspects of the online social media in the field of journalism.

Before going to final analyze of the data, answers to the five key questions were marked for getting results based on the goal of the study.

\section{CREDibility OF NEW MEdiA IN THE ERA OF JOURNALISM}

The credibility of the news published by the social online media is the main subject of this article. Number of previous researches and the observation of the journalism professionals indicate that the type of media is not the main factor in determining credibility; the main questions are by whom and how the information is being produced and disseminated. They (Metzger et al., 2003) also pointed out the similar concept that the media credibility is based on the source, the message, and the medium. A credible website could be a source of more credible information than a printed non-credible source, if the sources have a good reputation and brand name and follow the journalistic ethics and norms.

The concept credibility could be defined in various ways; in journalism generally it means that the information should be accurate, neutral, and trustworthy. Although the credibility research began in 1950 s in the fields of communication and psychology (Tseng \& Fogg, 1999), there is no exact definition till the date as the definitions of the term credibility is relative and differ each other. Some researchers (Al-Khalifa \& Al-Eidan, 
2011) gave the simple definition of credibility as believability and the people conception regarding credibility (Kim \& Johnson, 2009) is different for different types of media.

The social media enabled one person to communicate with thousands of people (Mangold \& Faulds, 2009) on net and share information. In many cases the readers get the information from unknown sources or they have very little information about the identity of the sources. The credibility depends on the source of information where the brand name is a factor to get idea regarding credibility of the news, although unknown sources may also supply credible information.

The changed form of the contents of the new media in the retelling process (Thurman, 2008) of the story and the activities of the professional journalists following the emergent of the social, the credibility of the re-telling process of the new and old media is almost same, if there is no distortion.

Some researchers (Lauer, 2011) and (Matheson, 2004) defined the characteristics of new media in different ways. Lauer's view is the new media were greeted by the public with enthusiastic fanfare and awe, but they also created new insecurities about the potential for unwanted exposure while Matheson termed the emergent practices as a journalism of linking rather than pinning things down. According to them, the new media are processing tools of knowledge, not a production tools.

Some researchers also defined the credibility as a multidimensional construct that measures the perceived believability of a message (article), source (journalist or media company), or medium (newspaper, website, radio station, etc.) (Mayer et al., 2010).

Some (Wathen \& Burkell, 2002) also agreed to determine the credibility by the interaction of three factors: source, message, and receiver. But the perception of the readers is also important to get idea of credibility about different types of information while some (Melican \& Dixon, 2008) are not interested to define all the information found online as news.

The Stanford guidelines include: accuracy of information, clear organization of the web site, trustworthiness of the people who stand behind the web site, easy-to-find contact information, web site usability, frequently updated content, absence of any promotional content, and freedom from error.

There are some negative impressions of the internet users to the online social media where the users reported extremely negative views about the reliability of web pages posted by individuals. The USC, Annenberg school of communication and journalism in California in its Digital Future Report 2010 showed that only 15 per cent of the social media users said most or all of the information on a webpage posted by individual is reliable and accurate (USC, 2011). Considering the above discussions it could be said that trustworthiness, accuracy, authenticity and expertise as foremost condition of web site credibility.

Based on the case studies in Finland, the article tries to focus on information credibility of the web based news from the ethical and journalistic perspectives. The reality is online social media credibility depends on the sources of information and the ways how to disseminate the information ensuring the transparency. 
The online social media have not enough scope to assure readers about the authenticity of their information through crosschecking at the initial stage but the information can be checked and corrected later even after making public, which enhance the credibility of the social media. The perspective of social media is different from that on traditional journalism because there is no systematic and organizational process to ensure authenticity and trustworthiness of information. The situation could be worse, if the person who sends information has no reputation or real identity. But on the other hand, the first-hand information produced by eyewitness or primary sources in the social media generally seems to be distortion free. The social media might be more trustworthy in some cases than the traditional media because the professional news gatherers of traditional media generally collect information from secondary or tertiary sources. Moreover, political and administrative pressure sometimes forces the traditional media to refrain from disclosing the real facts on some specific subjects, although Finnish media do not face such a problem. The social media are comparatively independent everywhere. Because of the easy access to the social online media anyone can post information and the lack of standards also may have a negative impact on the credibility of the information. It also can harm people's trust in social media in general

The term "news credibility" means that the information provided by the news media is authentic, unbiased, and written based on the facts. Despite having significant differences in perceptions about credibility between traditional and non-traditional online news, information always need to be presented objectively with authentic factual information even in the social media, if it is to be considered a part of credible journalism.

\section{IMPACT OF CITIZEN JOURNALISM ON NEWS MEDIA}

The term 'citizen journalism' refers to a range of web-based practices whereby 'ordinary' users engage in journalistic practices. But the private media turned into important sources of public information resulting significant impact on the mass media. The traditional news media are trying to cope with the news communication tools while the social media also using the traditional media contents in various ways.

Although citizen journalism was present in the past when the readers of newspapers were involved by expressing opinion and writing letters to the editor, the invention of internet created the opportunity for more active participation of the people through the citizen journalism.

Under the new phenomenon of the Citizen journalism, it is defined as the webbased practices where people engage in journalistic practice through disseminating information on net.

Some social media like Twitter, Facebook, Youtube, personal blog, could be treated as social media where general people share information, photo and video on the current events.

Researcher (Goode, 2009), however, sees 'citizen journalism' not an exclusively online, phenomenon, not confined to explicitly 'alternative' news sources but includes 'metajournalism' as well as the practices of journalism itself. 
The chief editor of the Lapin Kansa, Antti Kokkonen, during an interview conducted as a part of the study said that the social media are not limited in only the activities of the common people as he said: "Even the traditional media also started to act as like the social media in its flow of information"'.

Citizen journalism includes practices such as blogging based on current affairs, photo and video sharing, and posting eyewitness commentary on current events and participating in the news process without necessarily acting as 'content creators' (Goode, 2009) and the citizen journalism is seen to present a challenge to mainstream corporate media.

The media houses in Finland are also interested in using the content of citizen journalists when they pick up information and photos from an event where a professional has missed it.

Erkki Hujanen, community news editor of Kaleva said that many people get information only from social media now. They need not to read or hear main news media.

But, if the people use an item directly from social media, there could be a risk of credibility because there is no gatekeeping process on the social news sites such as Facebook, Twitter, YouTube, etc. Citizen journalism and social news sites are producing a huge amount of content privately without organizational shape and, in reality; it may be also a risk to keep social media out of journalism because of its impact globally.

The readers, users and audiences tend not to use a source that they do not trust. Despite the rapid growth in the use of online information sources, there is still an argument against the credibility of the Internet because of its easy access and lack of standards for publishing. Any Internet user could become a knowledge producer and have a voice in the virtual world, developing a new form of journalism. Some journalists, however, are yet to take the role of social media seriously and considered the citizen journalism as a new phenomenon of the flow of information but not a part of journalism.

They believed that the social media are not full-fledged news media. Margareta Björklund of the Österbottens Tidning termed the social media as mainly the media for entertainment and sometimes served the purpose of public relations.

Pointing out the lack of credibility, Margareta Björklund held the freeness and unregulated flow of information responsible for the credibility of social media. As she said: "The free and unregulated flow of information on the web could make it difficult to obtain credible information and even lead to false information" 2 .

The above discussions showed a clear scenario that the social media put significant impact on the traditional news media from different aspects. In one hand, it already challenged the traditional media by producing huge information quickly. On the other hand, the circulation of the printed newspapers is declining gradually, particularly where the access of internet is available, prompting the traditional newspapers to think alternative ways for survival. The established media houses in Finland, however, see the change

\footnotetext{
'Antti Kokkonen, Editor in Chief, Lapin Kansa.

${ }^{2}$ Margareta Björklund, editor-in-chief of Österbottens Tidning.
} 
positively as they termed the situation as reality. Some of them also said that the strong position of the social media compel the tradition media houses to build up a coordination. Fruitful coordination in the future could bring positive results for both the social and traditional media to play role as news media.

\section{Professional Journalistic CONCEPT}

Expertise and knowledge in news production are very important to earn credibility. When a professional journalist gathers information for preparing news, it is natural that detailed information is collected, considering the expectation for the issues or events, including their significance and consequence. But if the information is gathered by a nonprofessional, it is very difficult to get all the necessary detail because they are not experts in this field. Skilled communicators maintain clear concepts about the structure of news and the ethical aspects of having the capacity to disseminate information as a professional.

But in this case there is also risk to put trust in news media completely. This is because journalists selectively choose some information over other information. Therefore, when trusting news media, people put their faith in specific selections (Kohring \& Matthes, 2007).

Although it is very difficult to give a judgment on some relative issues, whether the information is right or wrong, it could be made trustworthy by being presented with expertise and following some necessary queries about the information. The information of social media prepared by the amateur communicators may face questions about credibility, if there is lack of accuracy and the information is not put ensuring transparency.

Most of the journalists interviewed term the professionalism as an important factor in performing credible journalism. They pointed out the fairness, neutrality, and ethical codes of conduct as important factors for credible journalism. Where journalism is a profession, journalists consider all the information from journalistic viewpoints and evaluate the news value of the information from professional aspects. There are huge amounts of information and disinformation in the social news media and all of the information is not news.

Some researchers also said that the lack of the gatekeeping role could lead audiences to challenge the authority of journalism (Mitchelstein \& Boczkowski, 2009).Terming journalism a porous occupation, researcher (Lowrey, 2006) observed that professional organizations have laid down formal principles of ethical conduct. Professional journalists also play a useful role in news selection that has an influence to make decisions. Number of studies (Karlsson, 2011) also focused various activities as principle journalistic process where the researchers termed the gatekeeping, news selection, and editing as the key factors.

About the nature of online journalism, previous studies (Steensen, 2009) said there is no doubt that, as online journalism evolves, a complexity of style and genres emerges that broadens its diversity and hence the role of online journalists. The studies (Jacobson, 2012) also suggested that online journalism has the potential to incorporate new forms of expression but news organizations have yet to fully embrace these features. 
Although news, advertising, and public relations have their own characteristics, researchers (Diga \& Kelleher, 2009) do not see significant differences in social network use between those primarily performing public relations manager and technician roles.

This experiment asked the interviewees about their perceptions of the social media as news media and most of them expressed positive impressions but they still think that the information of the social media need to re-check to ensure the authenticity. As Riikka Sipilä, online editor, of Keskipohjanmaa says: "On the question of credibility, the information of social media should be checked to ensure accuracy"3.

As the social media decoders are mostly amateur, they may put huge amounts of information in social media, but it sometime turns into disinformation and may not be able to fulfill people's desire. The professional can do it briefly. Professionalism can be also a vital factor to answer common public curiosity through the style of presentation. The professional style of description is also important because, in the professional structure, the most important information is presented first and the less important information is presented later. But the standard of media also depends on practicing the professionalism as there are number of traditional news media, who do not maintain proper journalism standard from the professional points of view.

Checking and editing before publishing is very important to ensure credibility. The copy editors check the information in a systematic process in the traditional news organization. But any process for editing information before publishing news is still absent in social media, although correction could be made there after publishing news. The communicator him or herself may check the information before publishing, although some time it's difficult to detect own mistake. The social media information provider may check the information from the online and develop the item further after getting some corrections from the audiences.

Following the arguments about professionalism and the gatekeeping process, it could be said that a significant change has taken place in the gate and the gatekeeper role in the era of social media, although it was not completely replaced by any specific editing system. Journalism and the role of journalists were undergoing substantial change prior to the remediation of journalism in digital media. Although it is not possible for the social media to follow the organisational process in gathering and preparing information, the credibility of acceptance of the information could be increased by following some correction methods and ensuring transparency of the information.

\section{TRADITIONAL NEWS MEDIA IN THE CHANGED SITUATION}

The traditional news media, especially newspapers, in Finland are found to think differently in the changed situation created following the massive expansion of the social news media. The media houses admitted that the circulation of the printed newspapers declined remarkably in recent years. The authority of Keskipohjanmaa said that the circulation of printed newspaper declined by about 10 percent during the last five year. The

\footnotetext{
${ }^{3}$ Riikka Sipilä, online editor, of Keskipohjanmaa.
} 
situation could be worsen further as adolescents are growing up with Internet and the Internet has become a central medium in everyday life for communication, educational resources, and other information (Jung et al., 2012).

Finnish journalists accepted the warning to traditional media. Antti Ylönen, the Web Manager of Lapin Kansa, says the new generation is reluctant to read the printed newspaper. He said: "The new generation is reluctant to read the printed newspaper and there is a possibility for the next generation will refrain completely from reading the printed newspaper" 4 .

The authorities of the media houses, however, said that despite reduction of the circulation of the printed newspaper, the overall readership increased as number of people read online version of the newspaper. The newspaper authorities are also facing a revenue crisis and reducing the number of employees, including journalists. The pressure on newspaper organizations to adopt new media strategies is hard to overstate (Bock, 2011).

But mass media developed their working pattern and changed structure following advancement of science and technology in different ages in the past and it is natural that the necessary steps would be taken by news media organisation to face the present crisis. Terming the media industry as dynamic researcher (Larsson, 2012) said that mergers and takeovers are occurring frequently in the media industry while (Mitchelstein \& Boczkows$\mathrm{ki}, 2009)$ the mainstream media became concerned with the presence of new entrants into the digital arena due to survive in the competition of supplying news immediately.

Some researchers, however, think that the speed of social media in disseminating news is higher than the digital version of traditional media. In this regard (Thurman, 2008) the online versions of the mainstream media are facing accusation of being slow to respond to the social media.

The view of Finnish journalist Antti Ylönen regarding the interest of young people to the online social media is also supported by researchers (Spyridou \& Velgis, 2008) as the Internet is the medium with the most success in attracting young people to news. The traditional media have been facing increasing trouble since the 1980 s. (Chan et al., 2006) and the negative judgment of online news sites can be partially a result of a will to defend the established authority of one's own profession and reaffirm blurring institutional boundaries.

The Finnish journalists express different opinions regarding the future of the traditional newspapers. Pointing out the professionalism, ethical aspects and deepness of the information, they believe that newspapers are overwhelmingly dominant in the actual gathering and reporting of news. They believe it will survive in any form; as Erkki Hujanen, community news editor of Kaleva says: "Newspapers would remain alive in any other format like the book"5.

Newspapers are turning into tabloid from the broadsheet but according to the traditional characterisation, the news function is rarely performed in tabloid newspaper. When the Finnish newspaper houses are trying to cope with the situation and most of them are

\footnotetext{
${ }^{4}$ Antti Ylönen, web manager of Lapin Kansa.

${ }^{5}$ Erkki Hujanen, community news editor, the Kaleva.
} 
looking for alternative findings. Now newspapers are being published in both online and printed versions to keep old readers and attract new ones, creating totally new products to generate new revenue. Following the above arguments and the realisation of the journalism professionals interviewed, it could be said that the traditional media sensed the situation has been changed in the field of journalism after emergent of the social media, although some argued that the development of the electronic media like radio and television failed to cover the role of newspaper in the past. Some journalists, however, term the social media as private and media for entertainment but they also agreed that the social media could be a full-fledged news media in future. Besides introducing internet version and changing shape of the printed newspaper, the traditional newspaper also started to build up coordination with the social media in the changed situation. Newspapers are linking with Facebook, Twitter and other social sites and organising social media groups for their media as part of coordination. But from the commercial and revenue aspects the situation is still vulnerable for traditional media, although a newspaper house in Finland found to install new printing machine spending huge amount of money as they believe the printed newspapers would be viable commercially at least for next few decades. But it is not unlikely that they may stop the printed version in future as like the global reputed newspaper, Newsweek already stopped printed version since the end of 2012.

\section{FindiNGS AND RESULTS}

The data showed that nine respondents out of 12 journalists term the social media information as credible; one terms the social media non-credible and two term the social media information partially credible. Three, out of the nine, who term the social media credible, however, treat the social media conditionally credible. One journalist also says the trend seemed to be credible while two other say that the credibility depends on sources where the sources should be identified with reputation.

Regarding the question of social media's role as a news media, eight respondents say the social media are part of news media but not full-fledged news media. Three journalists see the social media as a news media while one respondent does not consider the social media as news media at all.

The eight journalists, who term the social media as a part of new media say that the social media played a significant role as a source of primary information for the journalists and the people as well. They also opined that the social media would be full-fledged news media in future. Answering to the question regarding fact checking and editing, nine respondents say that lack of checking before making the information public is responsible for non-credible information in the social media. Terming the social media as different ways of communication, three journalists do not see the necessity for introducing gatekeeping process in the social media. They see the social media as private tools of communication.

Regarding the editing process eight respondents propose possible editing process for the social media. They said that the editing could be taken place in a soft way after publishing or before publishing the information. It could be checked by the readers, the 
source should ensure transparency by pointing out source of information and describing the process of gathering and preparing the information. The encoders may recheck the information from available online sources by own. Three respondents have no specific idea about probable editing for the social media information but they believe some sorts of editing process could be applicable to ensure credibility of the social media in future. One of the journalists, however, believes that it was not possible to edit the social media information and there was no necessity for editing the information produced by individual in the social media.

Regarding the possibility for practicing ideal journalism following ethics and journalistic norms, nine respondents say that the social media would get institutional status in future through earning more credibility and practicing professionalism. They say that the social media are already started cooperation with the traditional reputed news media and achieving more communication skill and credibility and disseminating information in journalistic way. The social media will be the mainstream news media and will be established by itself as alternative to the traditional media. But two journalists say the social media would run as per nature and there is no necessity for them to be established as a full-fledged news media while one does not know how the social media could get institutional shape to practice full-fledged journalism.

\section{Discussion}

All of the journalists in their interviews viewed that lack of checking or editing is one of the reasons for non-credible information in the social media but there are different of opinions regarding introducing editing or gatekeeping process in the social media. Most of them do not think social media as full-fledged news media at this stage but they believe it would be full-fledged news media in future. Presently they consider the new media as a means of getting primary sources of information, although they believe the social media as credible sources of information and social media would be more credible in future.

Antti Kokkonen says that the social media are credible but it needs to be more credible, which was supported most of the interviewees. As like his observation regarding the credibility, Antti Ylönen and Milla Sallinen see the social media as credible sources of information where the later two add that non-credible information is also available in tradition media.

Ylönen, Suvi Tanner, Riikka Sipilä and Sofia Grankull also do not see any deference between the credibility of traditional and social media but what is important they say is the credibility of the source of information as Ylönen says: "It is important that who is on the online"6.

Jukka Lehojärvi of Keskipohjanmaa also echoes the speech of Ylönen to this effect.

About the role of social media as a news media, Sallinen says the social media are now a part of traditional journalism as the professional journalists gather hints for news from the social media.

\footnotetext{
${ }^{6}$ Antti Ylönen, web manager of Lapin Kansa.
} 
Erkki Hujanen of Kaleva also says the same thing as he says: "The traditional media are gathering information from social media and professional journalists are doing work inside their offices"7.

Sipilä says that from the aspect of getting news, it is not important to see whether the media are traditional or social, the important thing is the contents. The better content providers certainly will play proper role in Journalism.

Erkki Hujanen, regarding the journalistic role says that the social media as credible as the traditional and number of people nowadays are getting information only from the social media and they do not use any traditional media for regular news update. Markku Mantila believes that the social media are credible and they will become more credible in future but it will take time.

Expressing similar observation, Janne-Pekka Manninen says that social media are credible and they could be more credible, if the way of gathering and disclosing information is transparent and open to the people. Although Lassi Jaakkola, Jukka Lehojärvi and Sofia Grankull see the social media as credible sources of information, still now they evaluate the social media as mainly the media of entertainment. They also believe that the credibility of the social media is increasing day by day. Lehojärvi says that ensuring the real identity of the source is very much important to ensure credibility. The observation of Margareta Björklund, however, is different to others as her impression is not positive on the credibility of social media, although she said that that some information of social media could be useful in some cases. Terming the social media information as generally personal and gossip, the journalist says that misleading information is available on political blogs, where people speak in favour of their own ideology, and the marketing sites of companies, where the intention is to persuade people. About the professionalism Margareta Björklund says: "People need to distinguish between marketing and journalism" 8 .

According to her statement, social media could not be a mass-media for news as they could be treated as private media like the opinion written in the personal diary or notebook.

But she points out the strength of the social media to disclose some information. She believes in some cases social media can provide information directly and specifically as they do not follow the ethics of journalism, which is not possible for the professionals as they have legal and ethical obligation. As an example, she points out the traditional media do not disclose the name of the under-trial accused or rape victims but social media can do it easily.

Sensing bright future of the social media in the field of journalism, Ylönen suggests either introducing gatekeeping process or some new form of checking for the social media information to achieve institutional shape.

In this point Sallinen says the social media present news in a lighter way and ensuring authenticity is important to be a serious media. She still sees lack of checking or

\footnotetext{
7 Erkki Hujanen, community news editor, the Kaleva.

${ }^{8}$ Margareta Björklund, editor-in-chief of Österbottens Tidning.
} 
editing as reasons for the non-credible information. Suvi Tanner in this regard says social media information could be edited after publishing. Erkki Hujanen says in this regard that there should be a fact-checking process but the checking could be done in a soft way. It should be checked by the sources themselves. If there are some contradictions, the news producers may gather knowledge from other sources before publishing it. Terming gatekeeping or editing in social media is important, the Kaleva journalist says that even the weblog, if it is made public, needs a gatekeeper while Mantila believes that after certain developments, a culture will be developed to find out ways ensuring credibility of the news presented by social media.

Janne-Pekka Manninen suggests that that social media could be more credible, if the way of gathering and disclosing information is transparent and open to the people. He believes that information from the nonprofessional journalists can fulfill the people's desire, if the information is objective and follow the ethical norms. Lassi Jaakkola, regarding the gatekeeping process speaks differently as he believes that it is not possible to check information on social media before making it public but it could be checked by the users when they will use it.

Most of the journalists believe that in the future, the social media could earn a brand name and become credible. Citizen journalists should gain knowledge about journalism because journalism cannot be done without education.

They believe that the social media can fulfill the public desire for information as the people may ask for more information on the same issue and can get it in phases, which is the strength of the social media. Lehojärvi and Sipilä see more opportunities for the social media to be a mainstream news media pointing out that professional journalists depend on their offices for various issues while the social media people are free from pressure, so they are in a much better position to disclose information close to the fact.

As Björklund does not admit the social media as a news media, she said that there is no necessity for introducing a gatekeeping system in the 'private' media. The Österbottens Tidning journalist says that the social media could be an alternative to the traditional media in a society where the media are not free, but in Finland news media are free to express everything. Grankull of the same newspaper feels necessity for editing information before making public but as per her observation, it is not possible to edit because so many people are providing information from different places.

Above discussions make it clear that the social media are playing a role in the arena of journalism and providing the people with various information and news. Although there might be controversy regarding the process of practising journalism in social media from professional and ethical aspects, it could be said that the social media already emerged as a new communication tools and put significant impact on traditional news media. Though there are various informations in social media beyond news, it would not be justified, if the social media is treated only as the media for entertainment. Number of news like the death of Osama Bin Laden on May 2, 2011, abduction of Finnish couple in Yemen in 2013 and, Hudson plane crush on January 15, 2009 were already broken by the social media in the past and still the news media are getting number information from different social media. 
Regarding the gatekeeping or fact checking process, any well organised structure of editing is yet be established in social media but some ways of sporadic corrections are on. It is likely that suitable structured fact checking process would be introduced in future when the social media would practise more journalism with credibility and professionalism. Then the practices will lead to social media to get institutional shape.

\section{Conclusion}

Most of the journalists, interviewed for the study emphasize the necessity for editing the information before making it public as they observe that lack of editing is responsible for non-credible information in the social media. Few of them, however, term the social media as generally private and its nature is different to the mass media, so there is no necessity for introducing a gatekeeping system there. Some interviewees point out the scope for editing social media information after publishing news by following comments of the readers while some suggest the producers themselves should check the information from other available sources on the net before disclosing the information. There is very little room for separating the traditional and social media from the aspect of credibility because the credibility of media depends on the sources and news producers as non-credible and misleading information found in both the printed and digital versions of traditional media. As like opinions of the Finnish journalists, it could be said that despite disseminating huge news and being a good sources of primary information, the social media have yet to turn into full-fledged mass media for journalism due to absence of some vital journalistic norms and procedures. But the reality is the digital media are gaining popularity and their credibility is increasing gradually, which forecast the possibility of social media to be a full-fledged news media in future as the era of printed newspaper is on the brink. Still there are number of reasons to be confused about the credibility of the information of social media. Ensuring transparency and introducing a suitable editing process could make the social media more credible. There could be campaigning to create awareness among social media news producers about the ethics of journalism and people's right to freedom of expression in order to increase the credibility of citizen journalism. Considering the study based on the theme interviews, it could be said that recognition of the trustworthiness of social media is still far away due to the absence of assurance about some basic factors such as transparency, accuracy, neutrality, and ethics. Any sort of editing makes the news more credible compared to unedited information directly disseminated by an individual. The basic questions of transparency, trustworthiness, and accuracy of information are important from the aspect of fair journalism. If the information producers of social media have adequate knowledge about news value and maintain responsibility, the information could be more acceptable than information from other credible sources. The news producers may ensure transparency of the total process from gathering information to prepare the news in order to earn the trust of the readers, in addition to edit the information by the encoder own. Such kind of initiatives may increase the credibility level of social media. Besides that, it is time for communications 
and journalism researchers to find out other probable ways to ensure credibility of social media, either by introducing an effective gatekeeping process or ensuring credibility in other ways. If it is possible, the online news media could become credible full-fledged news media in future.

[The author is a PhD student at the University of Lapland, Finland. The article inspired by the author's doctoral research is a part of a research project entitled "Integrated media production with new modes of communications." The author wishes to express his gratitude to his supervisors Professor Riitta Brusila and Hannu Vanhanen for their comments on earlier version of the article.]

\section{REFERENCES}

Al-Khalifa, H. \& Al-Eidan, R. (2011) 'An experimental system for measuring the credibility of news content in Twitter', International Journal of Web Information Systems 7 ( 2): 131-133

Bock, M. (2011) 'Newspaper journalism and video: Motion, sound and new narratives', New media Q society 14(4): 600-616

Chan, J, Lee F. \& Pan, Z. (2006) 'Online news meets established journalism: how China's journalists evaluate the credibility of news websites', New Media a Society: 8: 925-947

Diga, M. \& Kelleher, T. (2009) 'Social media use, perceptions of decision-making power, and public relations roles', Public Relations Review, University of Hawaii, School of Communications.

Goode, L. (2009) 'Social news, citizen journalism and democracy', New Media Q Society 11: 1287-1305

Jacobson, S. (2012) 'Transcoding the news: An investigation into multimedia journalism published on nytimes.com 2000-2008', New Media Q Society 14 :867-885

Jung J., Lin, W. \& Kim, Y. (2012) 'The dynamic relationship between East Asian adolescents use of the Internet and their use of other media', New Media a Society 14:969-986

Karlsson, M. (2011) 'Flourishing but restrained- the evolution of participatory journalism in Swedish online news, 2005-2009', Journalism practice 5: 68-84

Kim, D. \& Johnson, T. (2009) 'A shift in media credibility', The International Communication Gazette וד (4) : 283-302

Kohring, M. \& Matthes, J. (2007) 'Trust in News Media : Development and Validation of a Multidimensional Scale', Communication Research 34: 231

Larsson, A (2012) 'Interactivity on Swedish newspaper websites: What kind, how much and why?', The International Journal of Research into New Media Technologies 18: 195-213

Lauer, J. (2011) 'Surveillance history and the history of new media: An evidential paradigm', New Media Q society 14(4): 566-582

Lowrey, W. (2006) 'Mapping the journalism-blogging relationship', Journalism7: 477-500

Mangold, W. \& Faulds, D (2009) 'Social media: The new hybrid element of the promotion mix', Kelley School of Business, Indiana University52: 357-365 
Matheson, D (2004) 'Weblogs and the Epistemology of the News: Some Trends in Online journalism', New Media of Society 6: 443-468

Melican, D. \& Dixon, T.( 2008) 'News on the Net : Credibility, Selective Exposure, and Racial Prejudice', Communication Research 35: 151

Metzger J., Flanagin, A., Eyal, K., Lemus D \&d McCann, R. (2003) 'Credibility for the $21^{\text {st }}$ century: Integrating perspectives on sources, message and media credibility in the contemporary media environment', P.J. Kalfleisch (ed.), Communication Yearbook 27: 293-335

Meyer, H., Marchionni, D. \& Thorson, E. ( 2010) 'The Journalist Behind the News: Credibility of Straight, Collaborative Opinionated, and Blogged "News", American Behavioral Scientist 54(2): 100-119

Mitchelstein, E. \& Boczkowski, J., (2009) 'Between tradition and change: A review of recent research on online news production', Journalism 10: 562-586

Moe, H. (2008) 'Dissemination and dialogue in the public sphere: a case for public service media online', Media Culture Society 30: 319

Rieh, S. \& Danielson, D. (2007) 'Credibility a multidisciplinary framework', Annual Review of Information Science and Technology 41 (1): 307-364

Spyridou, Paschalia. \& Veglis, A. (2007) 'The contribution of online news consumption to critical-reflective journalism professionals: Likelihood patterns among Greek journalism students', Journalism 9: 52-75.

Steensen, S. (2009) 'The shaping of an online feature journalist', Journalism 10: 702-718.

The USC, Annenberg school of communication and journalism in its Digital Future Report 2010, released on June 3, 2011: 40-181

Thurman, N. (2008) 'Forums for citizen journalists? Adoption of user generated content initiatives by online news media', New Media Society10: 139-156

The 2011 social media news survey report of the TEKGROUP, released on May 11, 2012

Tseng, S. \& Fogg B. (1999) 'Credibility and computing technology', Communication of the ACMI 42(5):39-44

Wathen, N. \& Burkell, J. (2002) 'Believe it or not: factors influencing credibility on the web', Journal of the American Society For Information Science and Technology 53(3): 134-144

$* * *$

Received: 14-03-2014

Accepted: 05-05-2014 